\title{
Phytochemical and GC-MS Analysis of Bioactive Compounds from Balanites aegyptiaca
}

\section{Isam M Abu Zeid ${ }^{1}$, Saed A Al-Thobaiti ${ }^{1}$, Ghada A EL Hag ${ }^{1}$, Sameera A Alghamdi ${ }^{1}$, Abdulrashid Umar ${ }^{2}$ and Omer Abdalla Ahmed Hamdi ${ }^{3 *}$}

${ }^{1}$ Department of Biological Sciences, Faculty of Sciences, King Abdulaziz University, Saudi Arabia

${ }^{2}$ Department of Chemistry, Faculty of Science, King Abdulaziz University, Saudi Arabia

${ }^{3}$ Department of Chemistry, Faculty of Science and Technology, Al-Neelain University, Sudan

*Corresponding Author: Omer Abdalla Ahmed Hamdi, Department of Chemistry, Faculty of Science and Technology, Al-Neelain University, Sudan.

Received: June 20, 2019; Published: July 24, 2019

DOI: $10.31080 /$ ASPS.2019.03.0352

\begin{abstract}
The aqueous extract of kernel and flesh of Balanites aegyptiaca were prepared, both were separately identified using GC-MS analysis. The extract of Balanites aegyptiaca kernel indicated the presence of 20 compounds accounting for 99.99\%. The major compounds of the kernel including 9-Octadecenamide (29.79\%), 3-0-Methyl-d-glucose (21.03\%), 13-Docosenamide (20.51\%), saturated fatty acids $(8.09 \%)$ and unsaturated fatty acids (1.49\%), while the flesh extract revealed the presence of a total of 22 compounds accounting for 99.99\%. The major compounds were 3-0-Methyl-d-glucose (42.56\%), 9-Octadecenamide (18.02\%), 13-Docosenamide (13.11\%), saturated fatty acids (2\%) and unsaturated fatty acids $(1.05 \%)$. The amount of fatty acids in the kernel is higher than that of the flesh.
\end{abstract}

Keywords: Balanites aegyptiaca; Aqueous Extracts; GC-MS; Bioactive Compounds; Fatty Acids

\section{Introduction}

The phytochemicals are naturally found in medicinal plants, they possess defense mechanism and protect from several diseases. The preliminary phytochemical screening tests may be useful in the detection of these bioactive principles and successively leads to the drug discovery [1]. GC-MS is considered as one of the best technique for identifying the constituents of volatile matter, long and branched chain hydrocarbons, alcoholic acids esters and others substances [2].

Medicinal herbs and alternative medicines are safer, effective, available and cheap alternatives in comparison to synthetic therapy [3]. One of these potential herbal medicines which could be included in many developing countries healthcare program is Balanites aegyptiaca. The plant is widely used by traditional healers in rural areas of many countries [4-9].

The fruit of Balanites aegyptiaca is partly long, narrow drupe, 2.5 to $7 \mathrm{~cm}$ tall and 1.5 to $4 \mathrm{~cm}$ diameter. The immature fruit is green and tomentose, turning yellow and glabrous when mature.
The mature fruit consists of four layers: the outer layer epicarp, the fleshy pulp mesocarp, the wood shield endocarp and the seed kernel [10]. The pulp is bitter-sweet and edible. The kernel is 1.5 to $3 \mathrm{~cm}$ long, light brown, fibrous, and very solid. It constitutes up to $60 \%$ of the fruit. There are 500 to 1500 seeds $/ \mathrm{kg}$ [7]. The edible seed kernel is oil-rich part of the fruit and contains 4 main different fatty acids. Two are unsaturated fatty acids named oleic acid and linoleic acid. The other are two saturated fatty acids known as palmitic acid and stearic acid. The percentage of unsaturated fatty acids in the kernel oil to the saturated fatty acids is 1:9 [11]. In order to scientifically corroborate the claim made by traditional healers of the therapeutic success of this plant species, the present study aimed to evaluate some of the biochemical components of Balanites aegyptiaca kernel and flesh.

\section{Materials and Methods}

\section{Plant material}

The plant material used in the present study was selected after an extensive ethnobotanical survey that involved interviewing 
traditional healers and literature survey. The fruits of Balanites aegyptiaca were obtained from Jeddah, Saudi Arabia. The plant was identified and authenticated by a plant taxonomist at the Department of Arid Land Agriculture, Faculty of Meteorology, Environment and Arid Land Agriculture, King Abdulaziz University, Jeddah, Saudi Arabia.

Preparation of aqueous extracts of kernel and flesh

The mesocarp (Flesh) of the desert date fruits (B. aegyptiaca, Lalob) was scraped manually by using sterile sharp surgical blade. The endocarp (woody part) was broken manually by using scissor, and the kernels (seeds) were then collected. Thereafter, the dried kernels were ground into powder using an electric blender and stored in an air tight container.

Briefly, a suitable weight of the crude powder of Balanites aegyptiaca (kernel, flesh) was placed in a stoppered container with water. They were separately allowed to stand at room temperature for a period of at least 3 days until the soluble matter has dissolved. The aqueous extracts were decanted into clean dry conical flasks and then filtered through Whatman No.1 filter paper by using a Buchner funnel. Rotary evaporator (Eyela A-10005 China) was employed for the efficient and gentle removal of solvents from samples. Then the mixture was strained, the marc (the damp solid material) was pressed. Finally, the complete dryness of the aqueous extract was carried out by freeze drying (Labconco USA). The dried samples were stored into air-tight containers for subsequent use.

\section{Gas chromatography-mass spectrometry (GC-MS) method}

The GC-MS system (Agilent Technologies) was equipped with gas chromatograph (7890B) and mass spectrometer detector
(5977A) at Central Laboratories Network, National Research Centre, Cairo, Egypt. The GC was equipped with HP-5MS column ( $30 \mathrm{~m} \times 0.25 \mathrm{~mm}$ internal diameter and $0.25 \mu \mathrm{m}$ film thickness). Analyses were carried out using helium as the carrier gas at a flow rate of $1 \mathrm{ml} / \mathrm{min}$ at a splitless mode, injection volume of $1 \mu \mathrm{l}$ and the following temperature program: $60^{\circ} \mathrm{C}$ for $2 \mathrm{~min}$; rising at $10^{\circ} \mathrm{C} /$ min to $280^{\circ} \mathrm{C}$ and held for $10 \mathrm{~min}$. The injector and detector were held at 250 and $300^{\circ} \mathrm{C}$, respectively. Mass spectra were obtained by electron ionization (EI) at $70 \mathrm{eV}$ and using a spectral range of $\mathrm{m} / \mathrm{z}$ 50-550 and solvent delay $3 \mathrm{~min}$. The identification of different constituents of aqueous extracts of Balanites aegyptiaca kernel and flesh were determined by comparing the spectrum fragmentation pattern with those stored in Wiley and NIST Mass Spectral Library data and also with published literature.

\section{Results and Discussion}

\section{GC-MS Analysis of Balanites aegyptiaca Kernel}

The GC-MS analysis of the aqueous extract of Balanites aegyptiaca kernel revealed the presence of a total of 23 compounds accounting for $99.99 \%$. The major compounds were 9-Octadecenamide (33.21\%), 3-0-Methyl-d-glucose (21.03\%). and13-Docosenamide (20.51\%), saturated fatty acids $(8.09 \%)$ namely: cyclohexanecarboxylic acid, hexadecanoic acid, methyl ester, heptadecanoic acid, 3-phenylpropyl ester, 16-methyl-, methyl ester, dodecanoic acid, 2,3-bis(acetyloxy) propyl ester, hexadecanoic acid, 2-hydroxy-1-(hydroxymethyl)ethyl ester and octadecanoic acid, 2-hydroxy-1-(hydroxymethyl)ethyl ester) and unsaturated fatty acids (1.49\%) namely 9,12-Octadecadienoic acid (Z,Z)-, methyl ester and 11-Octadecenoic acid, methyl ester) (Table 1).

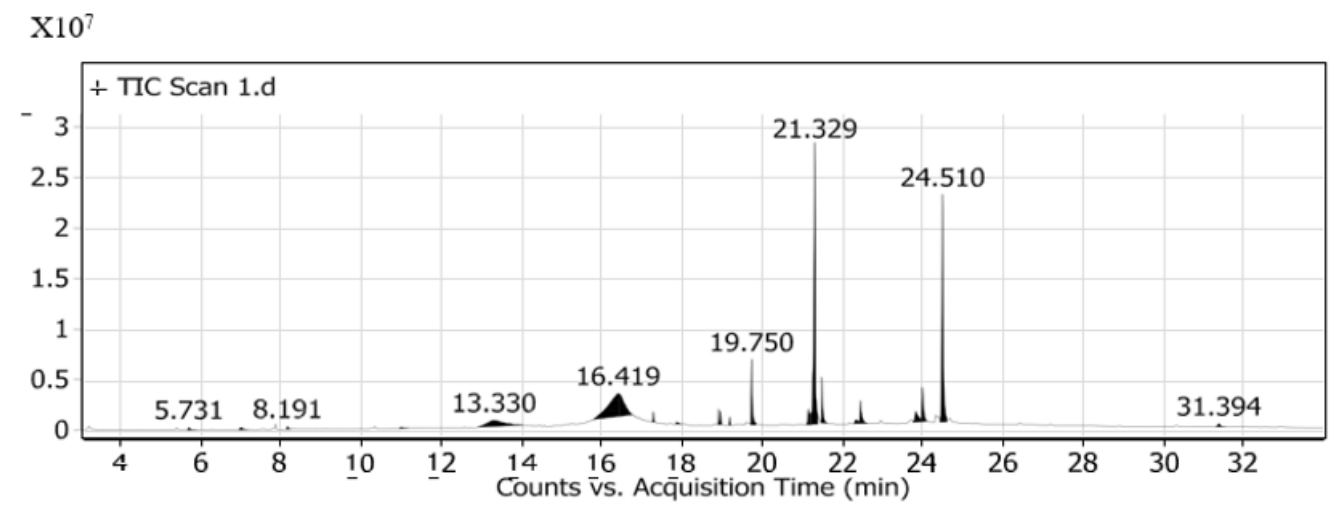

Figure 1: GC chromatogram of the aqueous extract of Balanites aegyptiaca kernel. 


\begin{tabular}{|c|c|c|c|c|c|c|}
\hline Peak & RT & Name & Formula & Area & Width & Area Sum \% \\
\hline 1 & 5.731 & Cyclohexanecarboxylic acid, 3-phenylpropyl ester & $\mathrm{C} 16 \mathrm{H} 22 \mathrm{O} 2$ & 1220596.15 & 0.24 & 0.41 \\
\hline 2 & 7.058 & Octadecane, 6-methyl- & $\mathrm{C} 19 \mathrm{H} 40$ & 1415741.13 & 0.235 & 0.47 \\
\hline 3 & 8.191 & $\begin{array}{c}\text { 3-[N'-(3H-Indol-3-ylmethylene)-hydrazino]-5-meth- } \\
\text { yl-[1,2,4]triazol-4-ylamine }\end{array}$ & C12H13N7 & 943598.28 & 0.131 & 0.32 \\
\hline 4 & 11.029 & Methyl 2,4-tridecadiynoate & $\mathrm{C} 14 \mathrm{H} 2002$ & 959825.33 & 0.246 & 0.32 \\
\hline 5 & 13.33 & Melezitose & C18H32016 & 19763513.04 & 1.144 & 6.61 \\
\hline 6 & 16.419 & 3-0-Methyl-d-glucose & C7H1406 & 62812087.2 & 0.997 & 21.03 \\
\hline 7 & 17.301 & Hexadecanoic acid, methyl ester & C17H3402 & 1712162.59 & 0.086 & 0.57 \\
\hline 8 & 17.884 & Octaethylene glycol monododecyl ether & С28H5809 & 963705.99 & 0.145 & 0.32 \\
\hline 9 & 18.931 & 9,12-Octadecadienoic acid (Z,Z)-, methyl ester & C19H3402 & 2306701.69 & 0.057 & 0.77 \\
\hline 10 & 18.983 & 11-Octadecenoic acid, methyl ester & C19H3602 & 2160150.95 & 0.062 & 0.72 \\
\hline 11 & 19.206 & Heptadecanoic acid, 16-methyl-, methyl ester & C19H3802 & 1266914.16 & 0.07 & 0.42 \\
\hline 12 & 19.75 & Hexadecanamide & C16H33NO & 13980904.14 & 0.137 & 4.68 \\
\hline 13 & 21.329 & 9-Octadecenamide & C18H35NO & 89034043.93 & 0.292 & 29.79 \\
\hline 14 & 21.501 & Octadecanamide & C18H37NO & 10221080.98 & 0.172 & 3.42 \\
\hline 15 & 22.376 & Dodecanoic acid, 2,3-bis(acetyloxy)propyl ester & C19H3406 & 2199643.02 & 0.132 & 0.74 \\
\hline 16 & 22.462 & $\begin{array}{l}\text { Hexadecanoic acid, 2-hydroxy-1-(hydroxymethyl)ethyl } \\
\text { ester }\end{array}$ & C19H3804 & 7610668.01 & 0.212 & 2.55 \\
\hline 17 & 23.847 & Glycidyl oleate & С21H3803 & 6813489.9 & 0.2 & 2.28 \\
\hline 18 & 24.007 & Octadecanoic acid, 2-hydroxy-1-(hydroxymethyl)ethyl ester & $\mathrm{C} 21 \mathrm{H} 4204$ & 10331235.97 & 0.169 & 3.46 \\
\hline 19 & 24.51 & 13-Docosenamide, (Z)- & $\mathrm{C} 22 \mathrm{H} 43 \mathrm{NO}$ & 61276981.76 & 0.177 & 20.51 \\
\hline 20 & 31.394 & gamma. Sitosterol & C29H500 & 1793583.82 & 0.267 & 0.6 \\
\hline
\end{tabular}

Table 1: GC-MS Analysis of Balanites aegyptiaca kernel.

\section{GC-MS Analysis of Balanites aegyptiaca Flesh}

The analysis of GC-MS of the aqueous extract of Balanites aegyptiaca flesh showed the presence of a total of 27 compounds accounting for $99.99 \%$. The major compounds were 3-0-Methyld-glucose (42.56\%), 9-Octadecenamide (18.02\%) and 13-Docose- namide (13.11\%), saturated fatty acids (2\%) namely hexadecanoic acid, 2-hydroxy-1-(hydroxymethyl)ethyl ester and octadecanoic acid, 2-hydroxy-1-(hydroxymethyl)ethyl ester) and unsaturated fatty acids (1.05\%) namely 9,12-Octadecadienoic acid (Z,Z)-, methyl ester, 11-Octadecenoic acid, methyl ester and Oleic Acid) (Table 2).

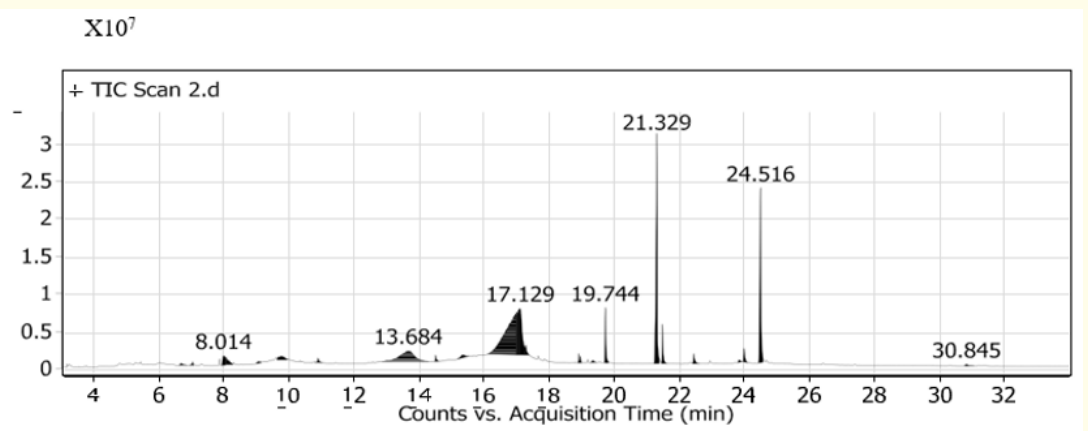

Figure 2: GC chromatogram of the aqueous extract of Balanites aegyptiaca flesh. 


\begin{tabular}{|c|c|c|c|c|c|c|}
\hline Peak & RT & Name & Formula & Area & Width & $\begin{array}{c}\text { Area } \\
\text { Sum \% }\end{array}$ \\
\hline 1 & 6.704 & DL-Arabinose & C5H1005 & 1537837.94 & 0.262 & 0.33 \\
\hline 2 & 7.07 & .beta.-D-Glucopyranose, 4-0-.beta.-D-galactopyranosyl- & $\mathrm{C} 12 \mathrm{H} 22011$ & 1269228.28 & 0.137 & 0.27 \\
\hline 3 & 8.014 & 4H-Pyran-4-one, 2,3-dihydro-3,5-dihydroxy-6-methyl- & $\mathrm{C} 6 \mathrm{H} 804$ & 10447576.28 & 0.217 & 2.23 \\
\hline 4 & 8.163 & 5-Methyl-2-ethylamino-2-thiazoline & C6H12N2S & 3033756.27 & 0.149 & 0.65 \\
\hline 5 & 9.084 & Maltose & $\mathrm{C} 12 \mathrm{H} 22 \mathrm{O} 11$ & 1472444.73 & 0.17 & 0.31 \\
\hline 6 & 9.782 & Melezitose & C18H32016 & 6608475.6 & 0.32 & 1.41 \\
\hline 7 & 10.915 & .beta.-D-Glucopyranose, 4-O-.beta.-D-galactopyranosyl- & $\mathrm{C} 12 \mathrm{H} 22011$ & 2255822.09 & 0.251 & 0.48 \\
\hline 8 & 13.684 & Melezitose & C18H32O16 & 46406265.91 & 1.45 & 9.9 \\
\hline 9 & 14.531 & 1H-Purin-2-amine, 6-methoxy-N-methyl- & C7H9N5O & 2209027.95 & 0.142 & 0.47 \\
\hline 10 & 15.35 & Desulphosinigrin & C10H17NO6S & 4024100.17 & 0.348 & 0.86 \\
\hline 11 & 17.129 & 3-0-Methyl-d-glucose & C7H1406 & 199550047.62 & 1.267 & 42.56 \\
\hline 12 & 18.932 & 9,12-Octadecadienoic acid (Z,Z)-, methyl ester & C19H3402 & 1978238.71 & 0.069 & 0.42 \\
\hline 13 & 18.977 & 11-Octadecenoic acid, methyl ester & C19H36O2 & 1513598.23 & 0.069 & 0.32 \\
\hline 14 & 19.366 & Oleic Acid & C18H34O2 & 1433176.25 & 0.19 & 0.31 \\
\hline 15 & 19.744 & Hexadecanamide & C16H33NO & 15348514.25 & 0.129 & 3.27 \\
\hline 16 & 21.329 & 9-Octadecenamide, (Z)- & C18H35NO & 84463884.89 & 0.166 & 18.02 \\
\hline 17 & 21.501 & Octadecanamide & C18H37NO & 11606072.48 & 0.172 & 2.48 \\
\hline 18 & 22.462 & $\begin{array}{l}\text { Hexadecanoic acid, 2-hydroxy-1-(hydroxymethyl)ethyl } \\
\text { ester }\end{array}$ & C19H3804 & 4417638.9 & 0.217 & 0.94 \\
\hline 19 & 23.847 & $\begin{array}{l}\text { 4-Hexyl-1-(7-methoxycarbonylheptyl)bicyclo[4.4.0]deca- } \\
\text { 2,5,7-triene }\end{array}$ & $\mathrm{C} 25 \mathrm{H} 40 \mathrm{O} 2$ & 1313403.89 & 0.139 & 0.28 \\
\hline 20 & 24.013 & $\begin{array}{l}\text { Octadecanoic acid, 2-hydroxy-1-(hydroxymethyl)ethyl } \\
\text { ester }\end{array}$ & $\mathrm{C} 21 \mathrm{H} 42 \mathrm{O} 4$ & 4953260.94 & 0.16 & 1.06 \\
\hline 21 & 24.516 & 13-Docosenamide, (Z)- & $\mathrm{C} 22 \mathrm{H} 43 \mathrm{NO}$ & 61448882.48 & 0.142 & 13.11 \\
\hline 22 & 30.845 & $\begin{array}{l}\text { Spirost-8-en-11-one, 3-hydroxy-, } \\
\quad(3 \beta, 5 \alpha, 14 \beta, 20 \beta, 22 \beta, 25 \mathrm{R})-\end{array}$ & $\mathrm{C} 27 \mathrm{H} 4004$ & 1457328.88 & 0.313 & 0.31 \\
\hline
\end{tabular}

Table 2: GC-MS Analysis of Balanites aegyptiaca Flesh.

The phytochemical screening tests might be an important tool for the detection of the bioactive principles which subsequently can leads to the drug discovery [1]. GC-MS is still considered as one of the best technique for identifying the constituents of volatile matter, long and branched chain hydrocarbons, alcoholic acids, esters and others organic substances [2].

The results of this study indicated that the GC-MS profile of the phytochemical constituents of the aqueous extracts of Balanites aegyptiaca kernel and flesh revealed the presence of 3-0-methylD-glucose (3-OMG), 9-Octadecenamide, 13-docosenamide, saturated and unsaturated fatty acids. 3-0-methyl-D-glucose (3-OMG) is a nontoxic, non-metabolizable glucose analogue. It is effective in reducing the toxicity of streptozotocin and protection of the pancreatic beta cell against the toxic action of alloxan [12].

9-octadecenamide is an oleamide, an amide derived from oleic acid biosynthesis [13]. Cheng et al. [14] reported both antioxidative and hypolipidemic bioactivity of 9-octadecenamide obtained from methanolic fractionate of mountain celery seed oil. The author's results showed a significant decrease in serum triglyceride, total cholesterol, lipoprotein cholesterol, low-density and hepatic triglyceride. 9-octadecenamide has been studied as a potential medicinal treatment for mood and sleep disorders [15]. 
On the other hand, 13-docosenamide is an amide of docosenoic acid, also called erucylamide, was reported to be capable of sleeplike induction [16].

Recent studies highlight the properties of bioactive compounds in functional foods, such as polyunsaturated fatty acids (PUFAs) especially omega-3 fatty acids [17]. The edible seed kernel of Balanites aegyptiaca is oil-rich part of the fruit and contains 4 main different fatty acids. Two are unsaturated fatty acids named oleic acid and linoleic acid. The other are two saturated fatty acids known as palmitic acid and stearic acid [11,18,19]. PUFAs have been correlated with a reduced risk of diabetes and improved human health [20,21]. Long chain omega-3 fatty acids may reduce mortality in diabetic patient's trough reduction of blood triglycerides, platelet aggregability and improving endothelial functions [22,23].

The beneficial effects of PUFA have been extensively studied $[17,20]$. These benefits were evidenced by the regulation of metabolic and inflammatory pathways, cardiovascular diseases, as well as in glucose homeostasis and insulin sensitivity among others $[24,25]$. PUFAs were known to increase some oxidant cleavage pathways and can also act as antioxidants [26]. Experimental studies showed that the PUFAs in cell membrane are prone to attack by free radicals due to the presence of stable multiple bonds [27].

\section{Conclusion}

Based on the above results, the Balanites aegyptiaca may be a very useful source of bioactive compounds for treating various diseases, therefore, further studies are highly emphasized in order to isolate, identify and elucidate these active components. kernel and flesh of Balanites aegyptiaca indicated some similarity in the presence of their chemical compounds such as 3-0-Methyl-dglucose and 9-Octadecenamide.

\section{Bibliography}

1. Subashini S., et al. "Phytochemical and GC-MS analysis of bioactive compounds from Borassus flabellifer Linn root". European Journal of Molecular Biology and Biochemistry 2 (2015): 148-152.

2. Nostro A., et al. "Extraction methods and bioautography for evaluation of medicinal plant antimicrobial activity". Letters in Applied Microbiology 30.5 (2000): 379-384.
3. Kooti W., et al. "The role of medicinal plants in the treatment of diabetes: A systematic review". Electronic Physician Journal 8.1 (2016): 1832-1842.

4. Dwivedi A., et al. "Anthelmintic activity of root bark of Balanites aegyptiaca (L.) Del. Ethnobot". Leaflets 13 (2009): 564567.

5. Jagtap SD., et al. "Traditional ethnomedicinal knowledge confined to the Pawra tribe of Satpura hills, Maharashtra, India". Ethnobotanical Leaflets 13 (2009): 98-115.

6. Vijigiri D and Sharma PP. "Traditional uses of plants in indigenous folklore of Nizamabad district, Andhra Pradesh, India". Ethnobotanical Leaflets 14 (2010): 29-45.

7. Chothani DL and Vaghasiya HU. "A review on Balanites aegyptiaca Del (desert date): Phytochemical constituents, traditional uses, and pharmacological activity". Pharmacognosy Reviews 5.9 (2011): 55-62.

8. Rashad H., et al. "Randomized double-blinded pilot clinical study of the antidiabetic activity of Balanites aegyptiaca and UPLC-ESI-MS/MS identification of its metabolites". Pharmaceutical Biology 55.1 (2017): 1954-1961.

9. Singh AP., et al. "A prespective review on a novel plant Balanites aegyptiaca (linn.)". Journal of Pharmaceutical and Biological Sciences 5.6 (2017): 273-277.

10. Al-Thobaiti SA and Abu Zeid IM. "Medicinal properties of desert date plants (Balanites aegyptiaca) - An overview". Global Journal Pharmaceutical 12.1 (2018): 1-12.

11. Okia CA., et al. "Physico-chemical characteristics and fatty acid profile of desert Date kernel oil". African Crop Science Journal 21.1 (2013): 723-734.

12. Nayak N and Padhy RN. "GC-MS Analysis of bioactive compounds and host-toxicity studies of Azolla caroliniana symbiotic with the cyanobacterium Anabaena azollae". Indian Journal of Pharmaceutical Education 51.S2 (2017): S24-S33.

13. Iwu IC., et al. "GC-MS, Phytochemical and antimicrobial analysis of the leaf of Newboudia laevis P. Benth". International Journal of Innovative Research and Development 7.7 (2018): 242-250. 
14. Cheng M., et al. "Chemical synthesis of 9(Z)-Octadecenamide and its hypolipidemic effect: A bioactive agent found in the essential oil of mountain celery seeds". Journal of Agricultural and Food Chemistry 58.3 (2010): 1502-1508.

15. Iwu IC., et al. "Characterization of the volatile components of the leaf of Starchytarpheta cayennesis (Rich) Vahl”. International Journal of Herbs, Spices and Medicinal Plants 4.1 (2019): 41-49.

16. Molehin OR., et al. "GC-MS analysis of bioactive compounds in three extracts of Clerodendrum volubile P. Beauv leaves". Journal of Medicinal Plants Studies 5.5 (2017): 191-195.

17. Yoshimura EH., et al. "Functionality of cow milk naturally enriched with polyunsaturated fatty acids and polyphenols in diets for diabetic rats". PLoS. ONE 13.4 (2018): e0195839.

18. Gardette JL and Baba M. "FTIR and DSC studies of the thermal and photochemical stability of Balanites aegyptiaca oil (Toogga oil)". Chemistry and Physics of Lipids 170.171 (2013): 1-7.

19. Hassan DM., et al. "Evaluation of phytoconstituent of Balanites aegyptiaca (L) Del leaves and fruit mesocarp extracts". MOJ Bioorganic and Organic Chemistry 1 (2017): 00039.

20. Guadarrama-Lopez AL., et al. "Type 2 diabetes, PUFAs, and vitamin D: Their relation to inflammation”. Journal of Immunology Research (2014): 860703.

21. Muley A., et al. "Fatty fish or marine n-3 fatty acids for preventing DM? A systematic review and meta-analysis". Current Diabetes Reviews 10.3 (2014): 158-165.

22. Kuppusamy U., et al. "Glycaemic control in relation to xanthine oxidase and antioxidant indices in Malaysian type 2 diabetes patients". Diabetic Medicine 22.10 (2005): 1343-1346.
23. Toorabg F., et al. "Effects of omega-3 fatty acids supplement on antioxidant enzymes activity in type 2 diabetic patients". Iranian Journal of Public Health 45.3 (2016): 340-345.

24. Flachs P., et al. "The effect of n-3 fatty acids on glucose homeostasis and insulin sensitivity". Physiological Research Czech Republic 63.1 (2014): S93-S118.

25. Serhan CN., et al. "Resolving inflammation: Dual anti-inflammatory and pro-resolution lipid mediators". Nature Reviews Immunology 8.5 (2008): 349-361.

26. Poudyal H., et al. "Omega-3 fatty acids and metabolic syndrome: Effects and emerging mechanisms of action". Progress in Lipid Research 50.4 (2011): 372-387.

27. Butterfield DA., et al. "Structural and functional changes in proteins induced by free radical-mediated oxidative stress and protective action of the antioxidants N-tert-butyl-alphaphenylnitrone and vitamin E". Annals of the New York Academy of Sciences 854 (1998): 448-462.

\section{Volume 3 Issue 8 August 2019}

(C) All rights are reserved by Omer Abdalla Ahmed

Hamdi., et al. 